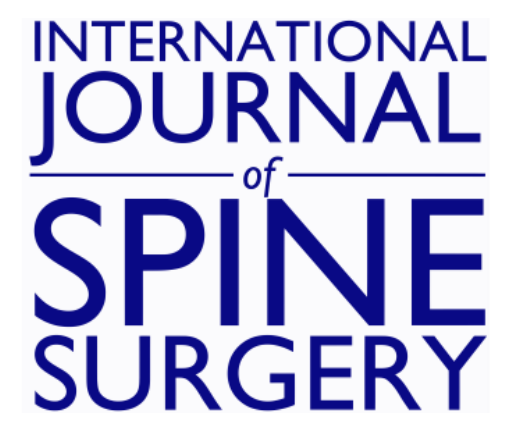

\title{
Iatrogenic Baastrup's Syndrome: A Potential Complication Following Anterior Interbody Lumbar Spinal Surgery
}

James J. Yue, Glenn S. Russo and Carlos A. Castro

Int J Spine Surg 2015, 9 ()

doi: https://doi.org/10.14444/2066

http://ijssurgery.com/content/9/66

This information is current as of April 26, 2023.

Email Alerts Receive free email-alerts when new articles cite this article. Sign up at:

http://ijssurgery.com/alerts

The International Journal of Shing Surgerih 2397 Waterbury Circle, Suite 1,

Aurora, IL 60504, Phone: +1-630-375-1432

(C) 2015 ISASS. All Rights Reserved. 


\section{latrogenic Baastrup's Syndrome: A Potential Complication Following Anterior Interbody Lumbar Spinal Surgery}

James J. Yue, MD, Glenn S. Russo, MD, MS, Carlos A. Castro, MD

Department of Orthopaedic Surgery, Yale School of Medicine, New Haven, CT

\section{Abstract}

Background

Baastrup's Syndrome is a condition that occurs when there is abnormal contact between two adjacent spinous processes resulting in back pain. An alteration in lumbar spinal alignment and/or adjacent segment compensatory motion is thought to be potential causative factors. The objective of this study was to present a case series of what appears to be iatrogenic Baastrup's Syndrome as a mid-to-late term complication following anterior lumbar interbody surgery.

\section{Methods}

A retrospective chart review was performed of all patients undergoing anterior lumbar surgery for either fusion or disc replacement to determine the prevalence of Baastrup's Syndrome.

Results

Over a 12-year period, 855 patients who had undergone an anterior approach for lumbar spine surgery were identified. Of them 8 patients with evidence of Baastrup's Syndrome were found; this demonstrated a prevalence of 0.9\%. Diagnostic injection was a helpful clinical tool in confirming the diagnosis of iatrogenic Baastrup's Syndrome. The partial removal of the impinging spinous processes resulted in excellent clinical relief.

\section{Conclusions}

Iatrogenic Baastrup's Syndrome may be an iatrogenic result of anterior lumbar surgery in small group of patients. Spinous process excision is a suggested treatment option. Further studies are necessary to explore the above phenomenon. This study is a Level 3 retrospective case series.

KEYWORDS: ANTERIOR LUMBAR SURGERY, SPINOUS PROCESS IMPINGEMENT, KISSING SPINE DISEASE, BAASTRUP'S SYNDROME VOLUME 9 ARTICLE 66 DOI: 10.14444/2066

\section{Introduction}

Anterior lumbar interbody surgical techniques, such as fusion and lumbar disc replacement, can be employed to treat a variety of spinal disorders. Indications for such an anterior surgery could include degenerative disc disease, spondylolisthesis, adult scoliosis or pseudo-arthrosis. Typically, complications secondary to anterior interbody surgery are described as being related to either the device or the approach. The main complications include vascular, viscous, and ureteral injury; as well as deep and superficial infection, hernia, deep venous thrombosis and subsidence..$^{1,2}$ However, posterior complications as the result of anterior lumbar surgery have also been described, and most commonly include pedicle fractures and radicular complaints..$^{1-4}$
Baastrup's Syndrome is a condition, which occurs when there is abnormal contact between two adjacent spinous processes with resultant back pain.-9 The condition was first described by Baastrup in $1933^{5}$ and recently has also been termed Kissing Spine Disease. ${ }^{10}$ The frequency of Baastrup's Syndrome increases with age and has a peak of incidence of $81 \%$ among patients older than 80 years. ${ }^{5}$ However, not all radiographic cases of spinous process impingement manifest themselves clinically.

Clinical symptoms and physical examination often reveal a distinct focus of midline pain and tenderness which is exacerbated on extension of the lumbar spine and subsequent impingement of the spinous processes. ${ }^{11}$ In rare cases, Baastrup's Syndrome can cause spinal stenosis. ${ }^{12,13}$ In some cases, magnetic res- 
onance imaging (MRI) may show edema and inflammation around the spinous process. ${ }^{11}$ The abutting of the spinous processes may create an adventitial bursa inflammatory response within the interspinous ligament and may result in instability of that segment. ${ }^{14}$ Computed tomography (CT) often reveals bony erosive changes. When physical examination along with the radiographic findings infer a diagnosis of Baastrup's Syndrome versus adjacent level degeneration, then a fluoroscopically guided injection can be performed to confirm the diagnosis and further delineate a specific pain-generator. ${ }^{11,15}$ Treatment may be conservative with analgesics and muscle relaxants and physical therapy. ${ }^{8}$

To the best of our knowledge, iatrogenic Baastrup's Syndrome causing recurrent low back pain following anterior lumbar interbody surgical procedures has not been previously described. In this manuscript we present a case series in which Baastrup's Syndrome occurred after anterior spine surgery.

\section{Materials and Methods}

Over a period of 12 years, our group retrospectively reviewed a single surgeon's experience (JJY) for the prevalence of Baastrup's Syndrome in all patients undergoing anterior lumbar surgery for either fusion or disc replacement. A total of 855 patients who underwent anterior lumbar approaches to the spine were first identified by CPT code. All operative approaches were primary exposures and were performed by the same vascular access surgeon via a paramedian retroperitoneal approach. Of the $855 \mathrm{pa}-$ tients, a total of 8 patients were identified by ICD-9 code as having been given the diagnosis of Baastrup's Syndrome occurring after anterior spine surgery. All patients underwent a thorough preoperative workup with repeated interviews, physical examination and imaging. Patients who had an exam and radiographic characterisics of Baastrup's Syndrome received a diagnostic corticosteroid injection in the interspinous space of interest to help differentiate interspinous impingement from adjacent level disease. Attenuation or resolution of the patient's pain after injection was considered diagnostic of Baastrup's Syndrome. For those patients positively identified with Baastrup's Syndrome, a partial spine process excision by the senior author (JYY) was then performed.

The partial excision of the spinous process was performed in the prone position on a fluoroscopic imaging table. A 3-4 cm midline incision was used to obtain bilateral exposure of the interspinous region of interest. Utilizing a Leksell rongeur and a burr, the inferior $1 / 3$ of the cranial spinous process and the superior $1 / 3$ of the caudal spinous process were excised down to the level of the lamina. If there was evidence of any laminar impingement, a partial laminectomy was also performed. Bone wax was placed over the bleeding bony edges and the wound was closed in a layered fashion. No post-operative bracing or extended periods of rehabilitation therapy were necessitated.

\section{Results}

The results of this case series are outlined in Table 1. Of the 8 patients who were included in this study, the average patient age was 51.5 years of age (range from 34 to 61 years). Patients presented on average 6.4 years after their most recent anterior lumbar surgery. X-rays and lumbar CT was ordered in all the patients pre-operatively in order to evaluate fusion or hardware displacement. All patient's complained of progressive symptoms that did not respond to conservative care. Diagnostic corticosteroid injection provided complete but temporary pain relief in all patients. All patients described resolution of low back pain after spinous process excision. The average post-operative follow-up for this cohort was 2.25 years.

\section{Representative Case Examples}

\section{Case Example A}

Patient A was 59-year-old male who presented with symptoms of back pain 2 years after an anterior lumbar interbody fusion at L5-S1 and an artificial disc replacement at L4-5 (Figure 1). An interspinous corticosteroid injection at the L4-5 resulted in complete pain relief of his lower back pain. Partial excision of the L4 and L5 spinous processes was utilized as a definitive and successful treatment. 


\section{Case Example B}

Patient B was a 61-year-old male who presented 5 years following L5-S1 disc replacement with 6 months of midline low back pain that was recalcitrant to non-operative therapy. His back pain was exacerbated in extension and provoked by palpation of the L4 spinous process. However, his imaging showed evidence of interspinous impingement at the L4-5 level, which was the level above the prior disc replacement (Figure 2). Injection in the L4-5 interspinous process space resulted in complete, but temporary relief in his back pain. An interspinous resection at L4-5 was then performed with complete pain relief.

\section{Case Example C}

Patient $\mathrm{C}$ was a 60 -year-old man with a history of lumbar disc disease and chronic low back pain who underwent an L5-S1 anterior spine fusion approximately 11 years prior to presentation. On his initial evaluation, he noted progressive low back pain that was elicited with palpation of the L4 spinous process. A CT scan revealed evidence of spinous process impingement at the L4-5 level (Figure 3). A diagnostic injection was performed and resulted in significant pain relief for a temporary period of time. A partial excision of the L4 and L5 spinous process was performed as a definitive therapy.

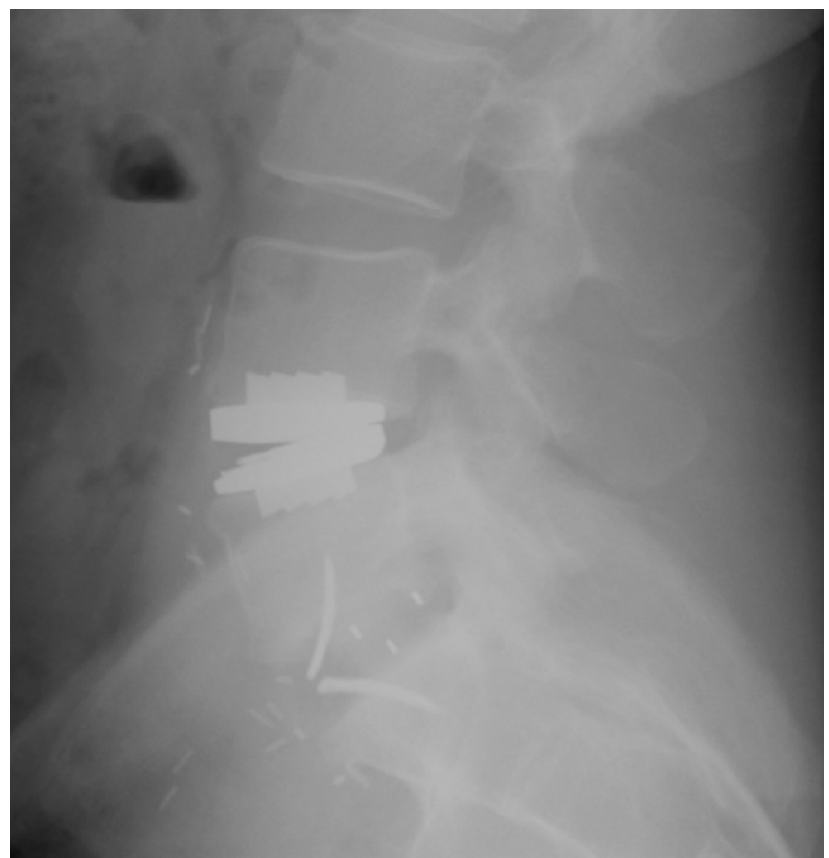

Fig. 1. Baastrup's Syndrome at the level of prior L4-5 disc replacement.

Table 1. Case summary. Abbreviations: low back pain (LBP), artificial disk replacement (ADR), anterior lumbar interbody fusion (ALIF).

\begin{tabular}{|c|c|c|c|c|c|c|c|c|c|}
\hline Gender & Age & Presentation & Surgery & Level & $\begin{array}{l}\text { Time Since Prior } \\
\text { Anterior Surgery }\end{array}$ & $\begin{array}{l}\text { Imaging with } \\
\text { Evidence of } \\
\text { Impingement }\end{array}$ & $\begin{array}{l}\text { Diagnostic } \\
\text { Injection with } \\
\text { Pain Relief }\end{array}$ & $\begin{array}{l}\text { Post-operative } \\
\text { Pain Relief }\end{array}$ & $\begin{array}{l}\text { Post-operative } \\
\text { Follow-Up }\end{array}$ \\
\hline M & 34 & LBP & 2-Level ADR & $\begin{array}{l}\text { L3-4 } \\
\text { L4-5 }\end{array}$ & 5 years & Y & $\mathrm{Y}$ & $\mathrm{Y}$ & 2 years \\
\hline $\mathbf{F}$ & 45 & $\begin{array}{l}\text { LBP with } \\
\text { extension }\end{array}$ & 2-Level ADR & $\begin{array}{l}\text { L4-5 } \\
\text { L5-S1 }\end{array}$ & 10 years & Y & Y & $\mathrm{Y}$ & 2 years \\
\hline M & 49 & LBP & $\begin{array}{l}\text { 2-Level Posterior } \\
\text { Fusion (separate } \\
\text { procedures) }\end{array}$ & $\begin{array}{l}\text { L4-5 } \\
\text { L5-S1 }\end{array}$ & $\begin{array}{l}21 \text { years and } \\
2 \text { years }\end{array}$ & $\mathrm{Y}$ & $\mathrm{Y}$ & $\mathrm{Y}$ & 2 years \\
\hline $\mathbf{F}$ & 51 & $\begin{array}{l}\text { LBP with leg } \\
\text { pain }\end{array}$ & 3-Level ADR & $\begin{array}{l}\text { L3-4 } \\
\text { L4-5 } \\
\text { L5-S1 }\end{array}$ & 6 years & Y & $\mathrm{Y}$ & $\mathrm{Y}$ & 2 years \\
\hline $\mathbf{F}$ & 53 & LBP & 3-Level ADR & $\begin{array}{l}\text { L3-4 } \\
\text { L4-5 } \\
\text { L5-S1 }\end{array}$ & 10 years & Y & Y & $\mathrm{Y}$ & 2 years \\
\hline M & 59 & LBP & ADR and ALIF & $\begin{array}{l}\text { L4-5 } \\
\text { L5-S1 }\end{array}$ & 2 years & Y & Y & $\mathrm{Y}$ & 2 years \\
\hline $\mathbf{M}$ & 60 & LBP & ALIF & L5-S1 & 11 years & $\mathrm{Y}$ & $\mathrm{Y}$ & $\mathrm{Y}$ & 2.5 years \\
\hline M & 61 & $\begin{array}{l}\text { LBP with } \\
\text { extension }\end{array}$ & ADR & L5-S1 & 5 years & Y & $\mathrm{Y}$ & $\mathrm{Y}$ & 2.5 years \\
\hline
\end{tabular}

Downloaded from http://ijssurgery.com/ by guest on April 26, 2023 


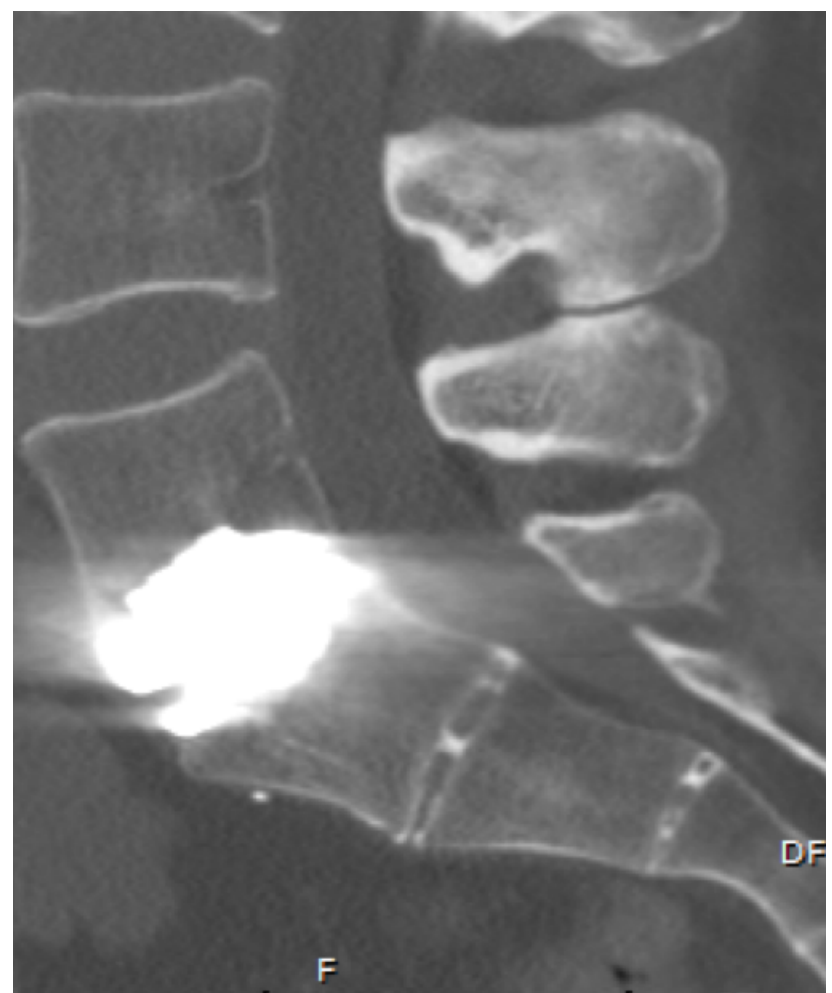

Fig. 2. Area of focal spinous process impingement at $L 4-5$ above the level of prior disc replacement.

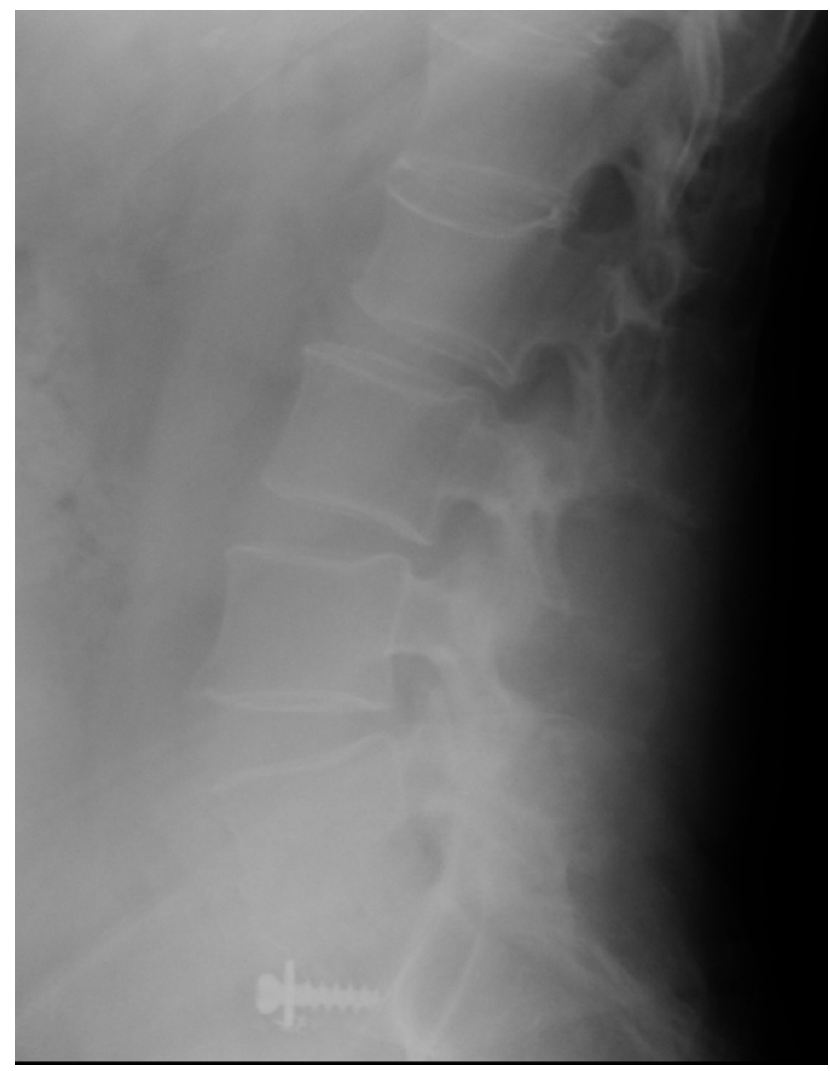

Fig. 3. Baastrup's Syndrome at L4-5 level following L5-S1 fusion.

\section{Case Example D}

Patient D was a 45-year-old female who presented with 6 months of low back pain and a surgical history notable for an L4-5 and L5-S1 disc replacement 10 years previously (Figure 4, Figure 5). Her back pain was exacerbated with extension and provoked by palpation of the L4 spine process region. A corticosteroid injection in the L4-5 interspinous process space was associated with temporary relief of her back pain. An interspinous resection at L4-5 was performed with successful pain relief.

\section{Discussion}

The anterior approach to the lumbar spine has been a well-established and accepted procedure for patients requiring fusion and disc replacement. However, there are several complications that are associated with this approach. Several issues, such as injury to the vasculature, kidney and bowel; as well as the potential for deep and superficial infection, hernia,

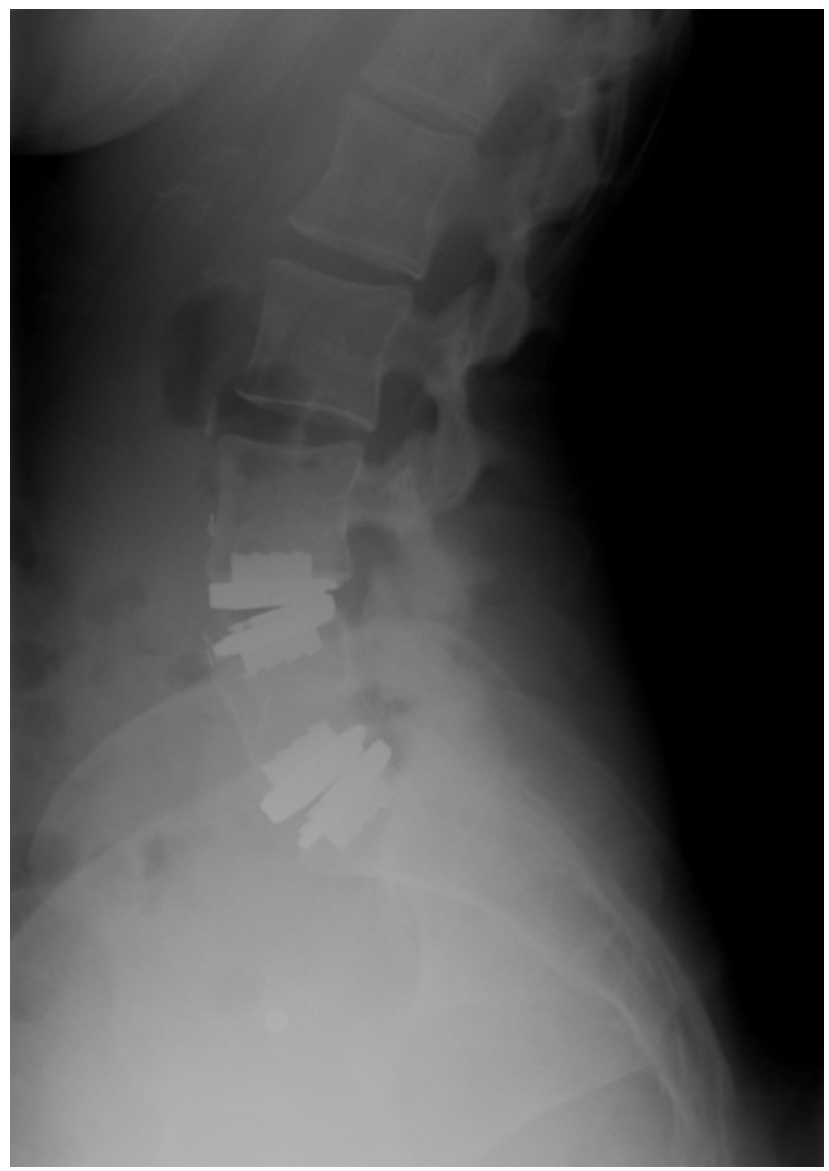

Fig. 4. Area of focal spinous process impingement at the $L 4-5$ level after disc replacement at L4-5 and L5-S1 levels. 
deep venous thrombosis, subsidence and pseudoarthrosis have all been described. ${ }^{1,2}$ However, we are not aware of any literature describing the delayed and apparently iatrogenic complication of Baastrup's Syndrome following anterior lumbar surgery.

In this study, we presented 8 patients who developed Baastrup's Syndrome after an anterior spinal surgery. The frequency of Baastrup's Syndrome increases with age and has a peak radiographic incidence of $81 \%$ among patients older than 80 years. ${ }^{5}$ However, in this study we found an average age of 51.5 years old. The prevalence in our series was $0.9 \%$. Also, almost all the cases occurred at, or one level above, the initial spinal surgery. Furthermore, the radiographs from patients in this case series are notable for the presence of normal disc height and absence of degenerative changes, which is contrasted by the more traditional presentation of Baastrup's Syndrome in the elderly where loss of disc height and degeneration appear to be the inciting factors. We believe that the symptomatic spinous process impinge-

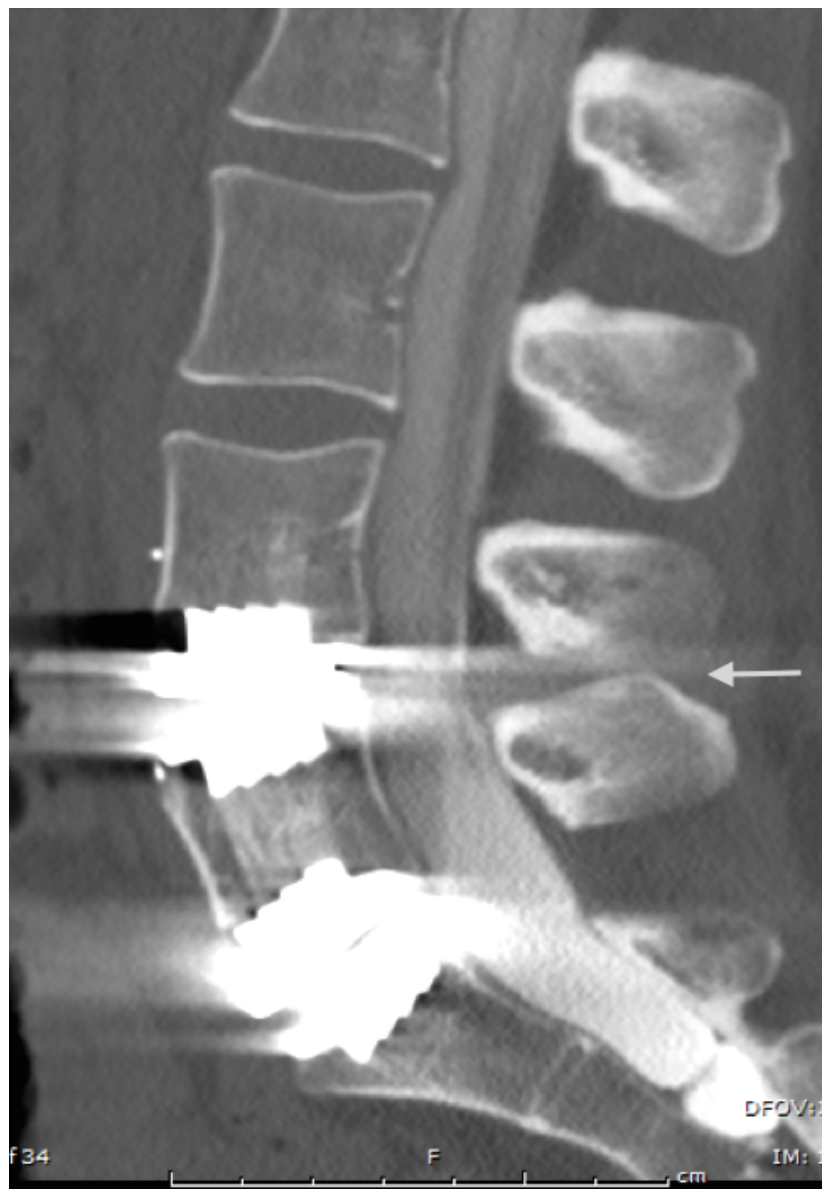

Fig. 5. CT representation of $L 4-5$ spinous process impingement ment could be a result of a global amplification of the normal lumbar lordosis as a result of the release of the anterior lumbar longitudinal ligament in patients who have undergone lumbar artificial disc replacement. However it is also possible that a fused segment was intra-operatively positioned in kyphosis necessitating a hyperextension effect at the adjacent level. An additional theory for the development of an iatrogenic spinous process impingement could be explained by the development of compensatory excess of mobility at the level above the sentinel surgery leading to excessive lordosis.

This study suffers from several limitations that are chiefly identified in the study design. This is a small cohort, retrospective case-series, and without prospective data, we are unable to definitively conclude that iatrogenic Baastrup's Syndrome exists as a consequence anterior lumbar surgery. However, as is a function of a retrospective case series, we believe that the data presented here merits sufficient evidence for the consideration of this issue as a potential complication to this surgical approach and thus deserves the benefit of a larger and more prospective study.

In summary, the objective of this paper was to present what appears to be a mid-to-late term complication after anterior lumbar surgery: iatrogenic Baastrup's Syndrome. An alteration in lumbar spinal alignment and/or adjacent segment compensatory motion may be potential causative factors. Radiographic findings in this case series did not include the presence of a pseudo synovial-like joint. Diagnostic injection did prove to be a helpful clinical tool in confirming the diagnosis of Baastrup's Syndrome. Ultimately, partial removal of the impinging spinous processes provided excellent clinical relief. Based on our experience in this small cohort, we recommend that the spinous process excision should be performed down to the level of the lamina to alleviate the offending impingement. In the future, prospective and large cohort studies may be helpful to identify risk factors and causes of this potential complication. 


\section{References}

1. Rothenfluh DA, Koenig M, Stokes OM, et al. Access-related complications in anterior lumbar surgery in patients over 60 years of age. European Spine Journal. 2014;23 Suppl 1:S86-92.

2. Jackson KL, Yeoman C, Chung WM, et al. Anterior lumbar interbody fusion: two-year results with a modular interbody device. Asian Spine Journal. 2014;8:591-8.

3. Whang PG, Sasso RC, Patel VV, et al. Comparison of axial and anterior interbody fusions of the L5-S1 segment: a retrospective cohort analysis. Journal of Spinal Disorders \& Techniques.

2013;26:437-43.

4. Goz V, Weinreb JH, Schwab F, et al. Comparison of complications, costs, and length of stay of three different lumbar interbody fusion techniques: an analysis of the Nationwide Inpatient Sample database. The Spine Journal. 2014;14:2019-27.

5. Kwong Y, Rao N, Latief K. MDCT findings in Baastrup disease: disease or normal feature of the aging spine? American Journal of Roentgenology. 2011;196:1156-9.

6. Gajdek D, Golebiowska B. [Baastrup syndrome of the lumbar spine in miners]. Chirurgia narzadow ruchu i ortopedia polska. 1976;41:171-4.

7. Lin E. Baastrup's disease (kissing spine) demonstrated by FDG PET/CT. Skeletal Radiology. 2008;37:173-5.

8. Singla A, Shankar V, Mittal S, et al. Baastrup's disease: The kissing spine. World Journal of Clinical Cases. 2014;2:45-7.

9. Nowak C. [A case of primary disease of Baastrup (author's transl)]. Polski przeglad radiologii i medycyny nuklearnej. 1977;41:295-6.

10. Okada K, Ohtori S, Inoue G, et al. Interspinous Ligament Lidocaine and Steroid Injections for the
Management of Baastrup's Disease: A Case Series. Asian Spine Journal. 2014;8:260-6.

11. Jang EC, Song KS, Lee HJ, et al. Posterior epidural fibrotic mass associated with Baastrup's disease. European Spine Journal 2010;19 Suppl 2:S165-8.

12. Rajasekaran S, Pithwa YK. Baastrup's disease as a cause of neurogenic claudication: a case report. Spine. 2003;28:E273-5.

13. Vicente J, Daguet E, Laredo JD. [Intraspinal bursitis secondary to Baastrup's disease: a rare cause of radicular compression]. Journal de Radiologie. 2010;91:729-31.

14. Yang A, Emig M, Akuthota V. Kissing spine and the retrodural space of Okada: more than just a kiss? PM \& R. 2014;6:287-9.

15. Mitra R, Ghazi U, Kirpalani D, et al. Interspinous ligament steroid injections for the management of Baastrup's disease: a case report. Archives of Physical Medicine \& Rehabilitation 2007;88:1353-6.

\section{Disclosures}

The authors declare no relevant disclosures.

\section{Corresponding Author}

James J. Yue, MD, Department of Orthopaedics and Rehabilitation, Yale School of Medicine, 800 Howard Avenue, P.O. Box 208071, New Haven, CT 06520. james.yue@yale.edu.

Published 23 November 2015.

This manuscript is generously published free of charge by ISASS, the International Society for the Advancement of Spine Surgery. Copyright $\odot 2015$ ISASS. To see more or order reprints or permissions, see http://ijssurgery.com. 